\title{
Implication of RNases PH in Turnover of M1 RNA
}

\author{
Yool Kim, ${ }^{a}$ Soon Kang Hong, ${ }^{\dagger, a}$ Jungmin Lee, Geunu Bak, and Younghoon Lee* \\ Department of Chemistry, KAIST, Daejeon 305-701, Korea. ${ }^{*}$ E-mail: Younghoon.Lee@kaist.ac.kr \\ ${ }^{\dagger}$ Department of Fire Service Administration, Chodang University, Chonnam 534-701, Korea \\ Received May 17, 2010, Accepted May 27, 2010
}

Key Words: M1 RNA, C5 protein, RNase P, RNase PH

\begin{abstract}
Escherichia coli RNase P was initially characterized as a tRNA-processing enzyme that removes extraneous 5 ' sequences from precursor tRNAs to generate mature 5 ' termini. ${ }^{1}$ In addition to tRNA processing, RNase $\mathrm{P}$ is involved in the processing of other non-tRNA substrates (e.g., 4.5S RNA and tmRNA) and the decay of several mRNAs. ${ }^{2-6}$. The RNase P holoenzyme is composed of two subunits, a large RNA subunit (M1 RNA, 377 nucleotides) and a small basic protein (C5 protein, 119 amino acids). M1 RNA is the catalytic subunit that can perform the reaction as a ribozyme in the absence of $\mathrm{C} 5$ protein in vitro, ${ }^{7}$ but both the protein and RNA components are essential in vivo. ${ }^{8}$ C5 protein stabilizes the catalytically active conformation of M1 RNA $^{9,10}$ and modulates its substrate specificity. ${ }^{11-16}$ Previously, we have shown that the turnover rate of free M1 RNA increases when C5 protein is sequestered by truncated M1 RNA transcripts, such as P12-deleted M1 RNA, in the cell, suggesting that the protein also functions as a metabolic stabilizer of M1 RNA. ${ }^{17}$
\end{abstract}

The size of C5 protein is only one-tenth of M1 RNA. Therefore, it is an interesting issue how this small protein can protect such a large RNA molecule from degradation. To address this issue, in this study, we tried to identify RNases responsible for the rapid turnover of free M1 RNA. For this purpose, we introduced into cells plasmid pLMd12, which overproduced P12deleted M1 RNA derivative as a C5 protein-interacting RNA, so that this plasmid-borne, overexpressed M1 RNA derivative could sequester $\mathrm{C} 5$ protein available for M1 RNA binding and thereby generate a protein-free form of M1 RNA within cells. ${ }^{17}$ Generally RNA degradation is initiated by endoribonucleolytic cleavage and RNase E plays an important role in this endoribonucleolytic cleavage. ${ }^{18,19}$ Therefore, we investigated the turnover rate of free M1 RNA in strains GW20 and GW11, which showed a temperature-sensitive RNase E phenotype and a RNase G mutant phenotype, respectively. ${ }^{20}$ Total RNAs prepared from GW20 and GW11 cells containing plasmid pLMdP12 were analyzed. The cellular levels of M1 RNA level after the treatment of rifampicin that inhibits transcription were monitored by northern blot analysis and then the metabolic stability of M1 RNA was assessed (Fig. 1). We observed no decrease of the M1 RNA stability in both cells. Surprisingly the M1 RNA stability was not decreased in the wild type control strain GW10 either. This contrasts our previous report that the sequestration of C5 protein via overexpression of C5 protein-interacting RNA, such as P12-deleted M1 RNA, reduces the metabolic stability

${ }^{\mathrm{a}}$ These authors contributed equally to this work. of M1 RNA. ${ }^{17}$ Since we had previously analyzed the M1 RNA stability in strain JM109, this discrepancy may be due to the difference of strains used. Therefore, we examined the M1 RNA stability in various strains with overexpressing P12-deleted M1 RNA(Fig. 2). MC1000 and DH5 $\alpha$ strains showed the decrease of M1 RNA stability like JM109 strain, while MG1655 strain showed little change of M1 RNA stability, as shown in GW10, suggesting that the overexpression of P12-deleted M1 RNA was not effective in MG1655 and GW10. One possibility for the lack of the M1 RNA stability-decreasing effect of P12-deleted M1 RNA in MG1655 and GW10 is that these strains would express P12-deleted M1 RNA at the lower level or C5 protein at the higher level than MC1000, JM109, and DH5 $\alpha$, and thereby C5 protein would not be sequestered enough to generate protein-free M1 RNA. To test this possibility, expression levels of the truncated M1 RNA and C5 protein were compared among these strains. Northern blot analysis showed that the levels of P12-deleted M1 RNA were comparable or even higher in MG1655 and GW10 than in JM109 and MC1000 (Fig. 3A), and western analysis showed that the levels of $\mathrm{C} 5$ protein in MG1655 and GW10 cells were also similar to those in JM109 and $\mathrm{MC1} 1000$ (Fig. 3B). These data suggest that the ineffectiveness of plasmid-borne P12-deleted M1 RNA on the M1 RNA stability in MG1655 or GW10 is not due to low expression of

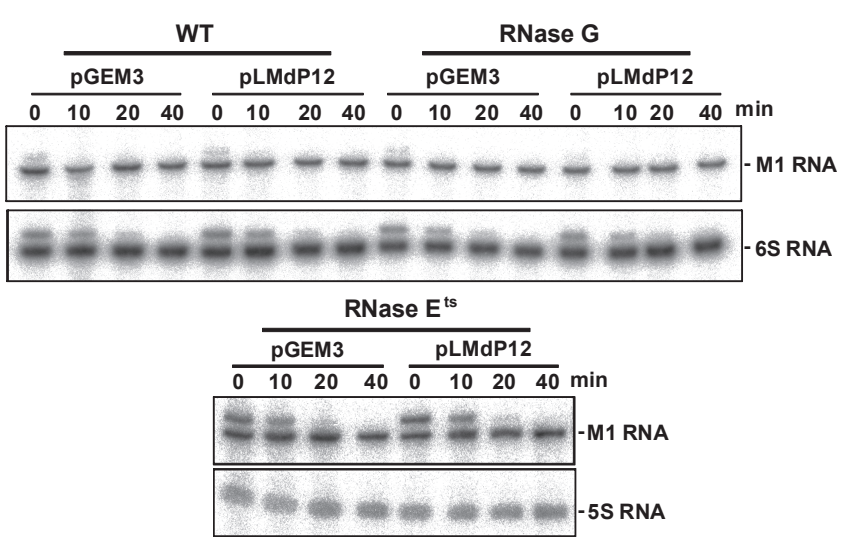

Figure 1. Effects on sequestration of $\mathrm{C} 5$ protein on M1 RNA stability in endoribonuclease-deficient cells. Total cellular RNA was isolated from strains GW10 (wild type), GW11 ( $\left.r n g^{-}\right)$, and GW20 ( $\left.r n e^{\text {ts }}\right)$ containing plasmids at the indicated times after the rifampicin treatment. Each RNA sample $(30 \mu \mathrm{g})$ was fractionated on a $5 \%$ polyacrylamide gel containing $7 \mathrm{M}$ urea and analyzed by northern blotting. A stem P12-specific probe was used as a probe for M1 RNA. 
(A)
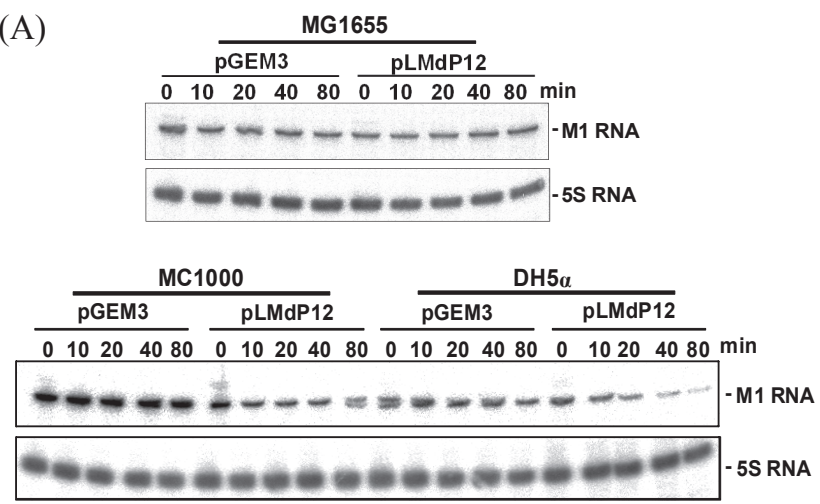

(B)

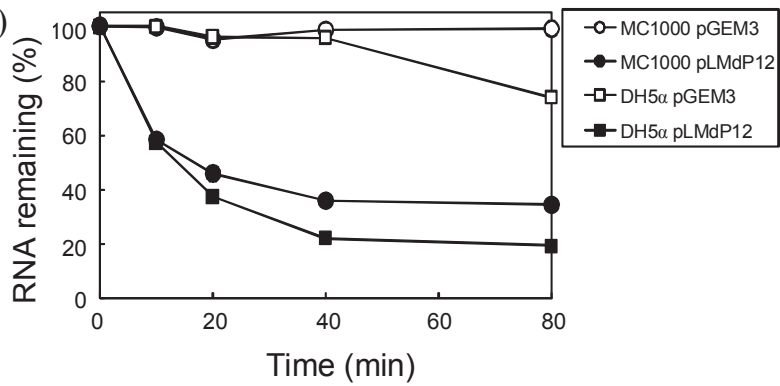

Figure 2. Comparison of effects of $\mathrm{C} 5$ protein sequestration on M1 RNA stability among various strains. (A) Total cellular RNA isolated from strains MG1655, MC1000, and DH5 $\alpha$ were analyzed as in Fig. 1. (B) The band intensity of endogenous M1 RNA was normalized to that of 5S RNA. The remaining RNA (\% of initial level) was calculated as a ratio of the amount of RNA at each indicated time to the amount of RNA at the rifampicin addition point.

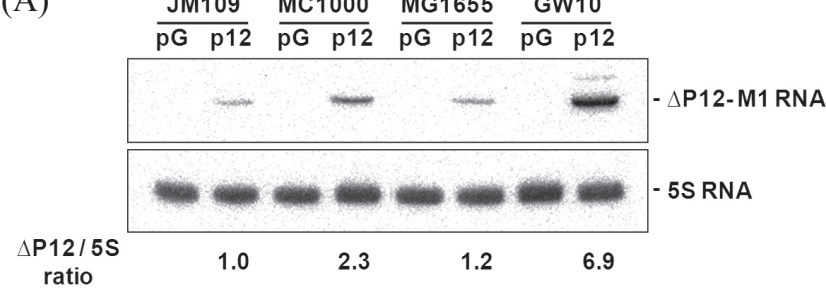

(B)

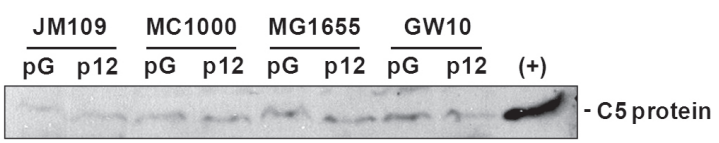

Figure 3. Comparison of expression levels of P12-deleted M1 RNA and C5 protein in different strains. (A) P12-deleted M1 RNA levels in different strains were analyzed by northern blotting with an anti-M1 RNA riboprobe. (B) C5 protein levels in different strains were analyzed by anti-C5 protein antibody. pG and $\mathrm{p} 12$ indicate cells containing pGEM as a control vector and pLMdP12 that expresses P12-deleted M1 RNA, respectively.

P12-deleted M1 RNA or high expression of C5 protein.

Then we examined whether $\mathrm{C} 5$ protein could be sequestered by overexpressed P-12 deleted M1 RNA to generate free M1 RNA in MG1655 or GW10. If C5 protein is sequestered as in JM109 cells containing pLMdP12, the cellular RNase P activity would be decreased and precursor tRNAs are accumulated. Therefore, we assessed the sequestration of $\mathrm{C} 5$ protein in $\mathrm{MG}$

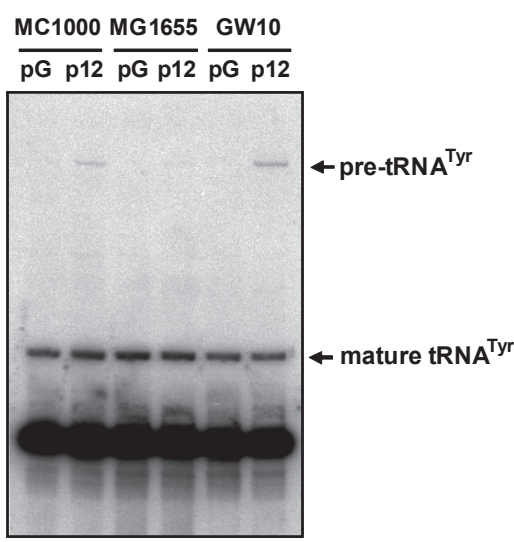

Figure 4. Effects of $\mathrm{C} 5$ protein sequestration on RNase P activity in MG1655 and GW10 cells. Total cellular RNAs prepared from MG1655 or GW10 cells containing pLMdP12 were subjected to northern blot analysis. The membrane was probed with an anti-tRNA ${ }^{\text {Tyr }}$ oligonucleotide. $\mathrm{pG}$ and $\mathrm{p} 12$ indicate cells containing $\mathrm{pGEM}$ as a control vector and pLMdP12 that expresses P12-deleted M1 RNA, respectively.

1655 and GW10 by analyzing the accumulation of tRNA ${ }^{\text {Tyr }}$ precursor (Fig. 4). Both cells containing pLMdP12 accumulated the tRNA precursor as did JM109, while cells containing the vector plasmid pGEM3 did not. This data suggests that $\mathrm{C} 5$ protein is sequestered by overexpressed P12-deleted M1 RNA derivative in MG1655 or GW10 and that the ineffectiveness of overexpressed P12-deleted M1 RNA on the M1 RNA stability would result from the defection of some RNase activities involved in degradation of protein-free M1 RNA.

We compared genotypes of MG1655, GW10, JM109, MC 1000 , and DH5 $\alpha$. We found that MG1655 and W3110 (the parental strain from which GW10 was derived) have the rph-1 genotype resulting from a C-terminal frameshift mutation in $r p h$ encoding RNase PH, an exoribonuclease,$^{21}$ while JM109, $\mathrm{MC} 1000$, and DH5 $\alpha$ have no mutation in the $r p h$ locus. The rph-1 mutation severely reduces RNase $\mathrm{PH}$ activity and has a polar effect on expression of the downstream $p y r E$ gene, reducing PyrE activity and causing partial pyrimidine starvation when mutant cells are grown in the minimal medium. ${ }^{21}$ The mutant RNase $\mathrm{PH}$ protein expressed by $r p h-1$ has a little smaller size than the wild type enzyme, with the C-terminal sequence of ESNPL instead of the normal GIESIVATQKAALAN sequence. The shorter size of the mutant enzyme is due to the frameshft caused by a one-base-pair deletion of the first base (G) of codon 223 (Fig. 5).

To examine whether RNase $\mathrm{PH}$ is involved in degradation of protein-free M1 RNA, we constructed an RNase PH expression vector, pAC-rph by cloning the $r p h$ gene into the pACYC 184 vector. Then we analyzed M1 RNA stability in cells containing both pLMdP12 and pAC-rph. The presence of pAC-rph, not the control vector pACYC184, reduced M1 RNA stability in the presence of pLMdP12. This reduction of M1 RNA stability was not observed with the control plasmid pGEM3 (Fig. 6). Therefore, it is likely that protein-free M1 RNA generated by the sequestration of $\mathrm{C} 5$ protein with overexpressed P12-deleted M1 RNA might be degraded by RNase PH. Since RNase PH is an exoribonuclease, this result suggests that degradation of 
(A)

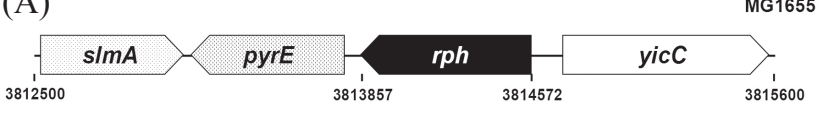

(B)

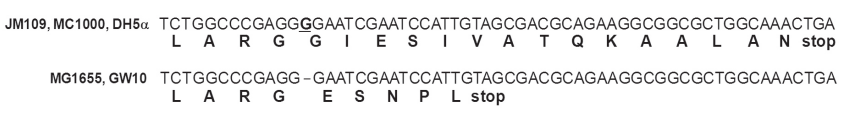

Figure 5. The rph-1 mutation. (A) Schematic representation of the locus of $r p h$ and its transcription unit in strain MG1655. (B) The $r p h-1$ gene generates a truncated $\mathrm{RNase} \mathrm{PH}$ at the $\mathrm{C}$-terminal region. The single deleted nucleotide of $r p h-1$ is underlined in bold in the wild type $r p h$ sequence.

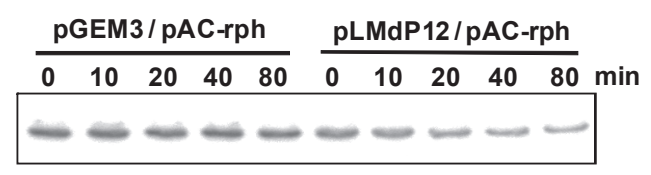

(B)

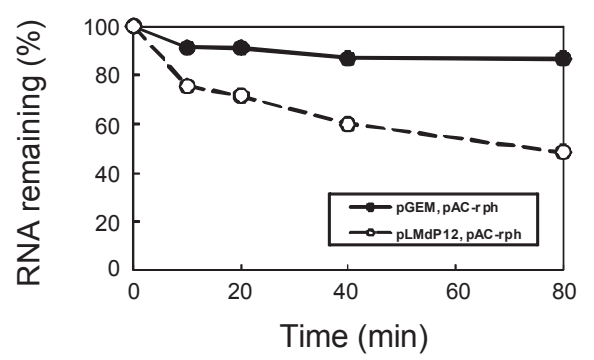

Figure 6. Restoration of instability of free M1 RNA in MG1655 by plasmid pAC-rph carrying the intact $r p h$ gene. Total cellular RNA was analyzed as in Fig. 1. pACYC184 was used as a control vector.

protein-free M1 RNA may start from the 3' end and that C5 protein may protect this degradation somehow although $\mathrm{C} 5$ protein does not seem to directly interact with the 3 ' end of M1 RNA. $^{22,23}$ Furthermore, our data imply that RNase PH might be a key exoribonuclease that participates in turnover of protein-free M1 RNA in the cell. However, it does not seem to be RNase $\mathrm{PH}$ alone that is responsible for degradation of proteinfree M1 RNA because the supply of RNase PH by a multicopy plasmid in MG1655 and GW10 did not fully recover the degradation sensitivity of protein-free M1 RNA to the level of JM109 or MC1000. Therefore, additional factors seem to be involved in maintaining the M1 RNA stability although they need to be demonstrated.

\section{Experimental Section}

Bacterial strains and plasmids. The E. coli $\mathrm{K}-12$ strains in this study are JM109 $\left[\mathrm{F}^{\prime}\right.$ proA $^{+}$proB ${ }^{+}$lacIq $\Delta$ (lacZ)M15 $\Delta$ (lac proAB) supE44 hadR17 recAl gyrA thi-1 endA1 relA1 el4lamda $],{ }^{24} \mathrm{MG} 1655\left[\mathrm{~F}^{-} \mathrm{rfb} 50 \mathrm{rph}-\mathrm{l}\right],{ }^{25} \mathrm{DH} 5 \alpha$ [supE44 lacU169 $\Delta$ (lacZ)M15 hadR 17 recAl endAl gyrA96 thi-1 relAl] ${ }^{26} \mathrm{MC}$ 1000 [F lamda araD139 $\Delta$ (ara-leu) $7697 \Delta$ (lacIY) 74 galU galK rpsL $],{ }^{27} \mathrm{GW} 10\left[\right.$ rng $^{+}$zce-726::Tn10Tc $\left.{ }^{r}\right],{ }^{20} \mathrm{GW} 11$ [rng::cat zce726::Tn10Tc $\left.{ }^{r} \mathrm{Cm}^{r}\right]{ }^{20}$ and GW20 [ams1 zce-726::Tn10Tc ${ }^{r} .^{20}$
Plasmid pLMdP12 was a derivative of the pGEM3 vector, which was capable of overexpressing a truncated M1 RNA. ${ }^{28}$ pAC-rph, was constructed by cloning the PCR product containing the $r p h$ sequence into the $N c o$ I- $E c o R I$ sites of the pACYC184 vector, which can co-exist with pGEM3 ${ }^{29}$ The $r p h$ sequence-containing PCR product carried the sequence spanning the region of -200 to +918 relative to the $r p h$ transcription start site. This PCR fragment was amplified using primers pAC-rph1 (5'-CATGC CATGGCGCATTTCCCAGGTTGCGCTC-3') and pAC-rph2 (5'-GGAATTCGATCGCGCCCGG-TATTAAA CAG -3').

Total cellular RNA preparation. JM109 cells containing plasmids were grown overnight $\left(37^{\circ} \mathrm{C}\right)$ in $\mathrm{LB}$ containing ampicillin $(50 \mathrm{mg} / \mathrm{mL})$, diluted 1:100 in the same medium, and grown to an $\mathrm{A}_{600}$ of approximately 0.5 at $37^{\circ} \mathrm{C}$. For RNA stability assays, rifampicin $(150 \mathrm{mg} / \mathrm{mL})$ was added to the cultures to stop transcription. Cultures were then analyzed at different time intervals. In case of temperature sensitive mutant GW20 strain, cells were grown overnight at $30{ }^{\circ} \mathrm{C}$, diluted $(1: 100)$ into the fresh media, and grown to an $\mathrm{A}_{600}$ of 0.5 . Cultures were incubated at $42{ }^{\circ} \mathrm{C}$ for $10 \mathrm{~min}$ before the rifampicin treatment. Total cellular RNA was prepared by hot phenol extraction, as described previously. ${ }^{30}$

Northem blot analysis. Northern blot analysis of RNA samples were performed, as described previously. ${ }^{31}$ The probes used for the M1 RNA detection were an anti-M1 RNA riboprobe, ${ }^{28}$ or a stem P12-specific oligonucleotide probe. ${ }^{17}$ tRNA $^{\mathrm{Tyr}}, 6 \mathrm{~S}$ RNA, and 5S RNA were also analyzed with antisense oligonucleotide probes. ${ }^{17}$ The stem-specific probe hybridized with intact M1 RNA, but not with P12-deleted M1 RNA.

Westem blot analysis. The $E$. coli cells containing plasmids were grown in LB containing ampicillin $(50 \mu \mathrm{g} / \mathrm{mL})$ at $37^{\circ} \mathrm{C}$ to an $\mathrm{A}_{600}$ of about 0.5. Cells were centrifuged down at $10,000 \mathrm{~g}$ for $10 \mathrm{~min}$. After harvesting the cells, the cell pellet was suspended in cold phosphate buffered saline $(\mathrm{pH} 7.2)$ containing $50 \mathrm{mM}$ Tris-HCl, $\mathrm{pH} 7.5,120 \mathrm{mM} \mathrm{NaCl}, 0.5 \%$ Nonidet P-40, $50 \mathrm{mM} \mathrm{NaF}, 200 \mu \mathrm{M}$ sodium orthovanadate, $1 \mathrm{mM}$ PMSF, and protease inhibitor (Complete ${ }^{\mathrm{TM}}$; Roche) for sonication. The soluble fraction of the sonicated cells was resolved on a $15 \%$ SDS-polyacrylamide gel and electrophoretically transferred to a nitrocellulose membrane (Amersham). Protein bands were immunostained with an anti C5 protein antibody, and were visualized by using an Enhanced Chemi-Luminesence Kit (Amersham).

Acknowledgments. This work was supported by the Korea Research Foundation Grant by the Korean Government (MOEHRD, Basic Research Promotion Fund) (KRF 2007-313C00454).

\section{References}

1. Robertson, H. D.; Altman, S.; Smith, J. D. J. Biol. Chem. 1972, 247,5243 .

2. Bothwell, A. L.; Garber, R. L.; Altman, S. J. Biol. Chem. 1976, 251,7709 .

3. Bourgaize, D. B.; Fournier, M. J. Nature 1987, 325, 281.

4. Komine, Y.; Kitabatake, M.; Yokogawa, T.; Nishikawa, K.; Inokuchi, H. Proc. Natl. Acad. Sci. USA 1994, 91, 9223.

5. Li, Y.; Altman, S. Proc. Natl. Acad. Sci. USA 2003, 100, 13213. 
6. Lee, J.; Kim, Y.; Hong, S. K.; Lee, Y. Bull. Korean Chem. Soc. 2008, 29, 1137.

7. Guerrier-Takada, C.; Gardiner, K.; Marsh, T.; Pace, N.; Altman, S. Cell 1983, 35, 849 .

8. Sakano, H.; Yamada, S.; Ikemura, T.; Shimura, Y.; Ozeki, H. Nucleic Acids Res. 1974, 1, 355.

9. Lumelsky, N.; Altman, S. J. Mol. Biol. 1988, 202, 443.

10. Buck, A. H.; Dalby, A. B.; Poole, A. W.; Kazantsev, A. V. ; Pace, N. R. EMBO J. 2005, 24, 3360.

11. Kirsebom, L. A.; Altman, S. J. Mol. Biol. 1989, $207,837$.

12. Kirsebom, L. A.; Svard, S. G. Nucleic Acids Res. 1992, $20,425$.

13. Peck-Miller, K. A.; Altman, S. J. Mol. Biol. 1991, 221, 1.

14. Hsieh, J.; Andrews, A. J.; Fierke, C. A. Biopolymers 2004, 73, 79.

15. Sun, L.; Campbell, F. E.; Zahler, N. H.; Harris, M. E. EMBO J. 2006, 25, 3998.

16. Liu, F.; Altman, S. Cell 1994, 77, 1093.

17. Kim, Y.; Lee, Y. FEBS Lett. 2009, 583, 419.

18. Jain, C. IUBMB Life 2002, 54, 315.

19. Kushner, S. R. J. Bacteriol. 2002, 184, 4658.

20. Wachi, M.; Umitsuki, G.; Nagai, K. Mol. Gen. Genet. 1997, 253,
515 .

21. Jensen, K. F. J. Bacteriol. 1993, 175, 3401.

22. Tsai, H. Y.; Masquida, B.; Biswas, R.; Westhof, E.; Gopalan, V. J. Mol. Biol. 2003, 325, 661.

23. Buck, A. H.; Kazantsev, A. V.; Dalby, A. B.; Pace, N. R. Nat. Struct. Mol. Biol. 2005, 12, 958.

24. Yanisch-Perron, C.; Vieira, J.; Messing, J. Gene 1985, 33, 103.

25. Blattner, F. R.; Plunkett, G., III.; Bloch, C. A.; Perna, N. T.; Burland, V.; Riley, M.; Collado-Vides, J.; Glasner, J. D.; Rode, C. K.; Mayhew, G. F.; Gregor, J.; Davis, N. W.; Kirkpatrick, H. A.; Goeden, M. A.; Rose, D. J.; Mau, B.; Shao, Y. Science 1997, 277, 1453.

26. Hanahan, D. J. Mol. Biol. 1983, 166, 557.

27. Casadaban, M. J.; Cohen, S. N. J. Mol. Biol. 1980, 138, 179.

28. Kim, S.; Kim, H.; Park, I.; Lee, Y. J. Biol. Chem. 1996, 271, 19330.

29. Chang, A. C.; Cohen, S. N. J. Bacteriol. 1978, 134, 1141.

30. Kim, Y.; Han, H.; Lee, J.; Kim, K. S.; Lee, Y. Bull. Korean Chem. Soc. 2007, 28, 1010.

31. Kim, K. S.; Sim, S.; Ko, J. H.; Lee, Y. J. Biol. Chem. 2005, 280, 34667. 